(2) Open Access Full Text Article

\title{
Systemic spread of tuberculosis after surgery for a splenic tuberculous abscess without postoperational antituberculosis treatment:
}

\section{a case report}

Dong Yan ${ }^{1,2}$

Cheng-Li Zhong'

Lan-Juan $\mathrm{Li}^{1,2}$

'State Key Laboratory for Diagnosis and Treatment of Infectious Diseases, The First Affiliated Hospital, School of Medicine, Zhejiang University, ${ }^{2}$ Collaborative Innovation Center for Diagnosis and Treatment of Infectious Diseases, Hangzhou, People's Republic of China
Correspondence: Lan-Juan Li State Key Laboratory for Diagnosis and Treatment of Infectious Diseases, The First Affiliated Hospital, School of Medicine, Zhejiang University, 79 Qingchun Road, Hangzhou 310003 , People's Republic of China Tel +86 I39 065 I24 210

Email ljli@zju.edu.cn

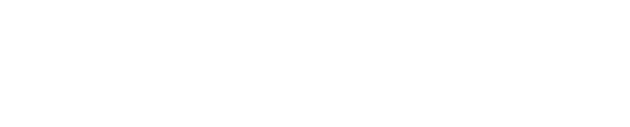

\begin{abstract}
Solitary splenic tuberculosis (TB) is rare, with less than ten cases ever being reported. The diagnosis is established by the pathological analysis of a biopsy from a surgical operation or from a fine-needle aspiration sample. Manifestations of splenic TB include low-grade fever, weight loss, abdominal pain, and diarrhea. This case, however, has no obvious symptoms, and multiple splenic tubercles were discovered during a routine physical examination. Splenic abscesses from TB were diagnosed after the operation. Postoperative spread of TB lead to cerebral tuberculous abscesses and pulmonary TB. Resolution was achieved with anti-TB therapy.
\end{abstract}

Keywords: solitary splenic tuberculosis, cerebral abscesses, lung tuberculosis, diagnosis, postoperative, antituberculosis treatment

\section{Case presentation}

The patient was a 38-year-old female, housewife, who was admitted on discovery of a splenic mass during a routine physical examination. She had no complaints of abdominal bloating, abdominal pain, cough, expectoration, weight loss, incompetent, etc. She had no family history of tuberculosis (TB) or contact with patients with TB. She had no history of steroid intake. An abdominal ultrasound showed several hypoechoic masses in the patient's spleen. Magnetic resonance imaging (MRI) indicated splenomegaly and multiple irregular intrasplenic masses without clear boundaries. Inhomogeneity was shown inside the masses, where T2-weighted images showed mainly high intensity signal, and low intensity signal was seen in the periphery around some of the masses. T1-weighted images showed mainly equal intensity, and slight hyperintensity was seen inside and around some of the masses. With a contrast-enhanced scan, no enhancement of the masses was seen, whereas the boundaries became clearer rendering a honeycomb appearance (Figure 1). Other significant laboratory tests included white blood cells of $4.8 \times 10^{9} / \mathrm{L}$, erythrocyte sedimentation rate of $30 \mathrm{~mm} / \mathrm{h}$, C-reactive protein of $8 \mathrm{mg} / \mathrm{L}$, human immunodeficiency virus test was negative, normal chest $\mathrm{X}$-ray, and a normal electrocardiogram. A decision was made to remove the spleen. During the surgery, the spleen was found to be enlarged with tense adhesions to the surrounding tissues and a significant amount of small tubercles on the surface of the left diaphragm, upper-left abdominal peritoneum, stomach, gastrosplenic ligament, splenic fossa, and the nearby greater omentum. A large amount of suppuration and 


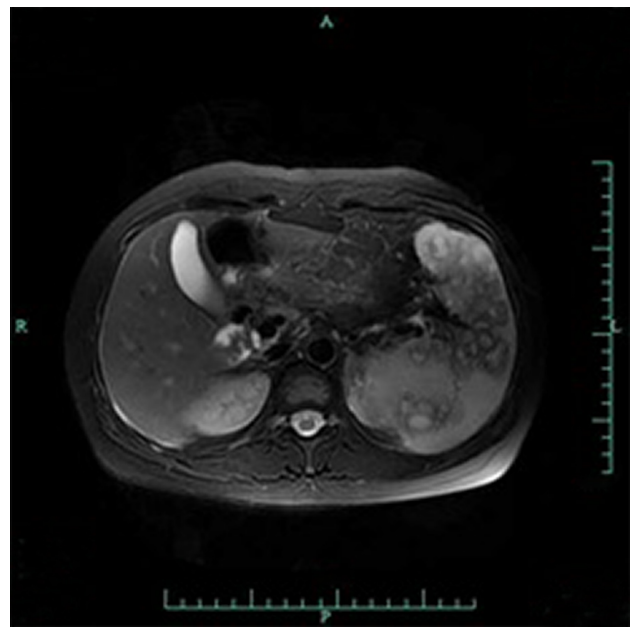

Figure I T2WI of splenic MRI showing high intensity signal, and low intensity signal in the periphery around some of the masses.

Abbreviations: MRI, magnetic resonance imaging; T2WI, T2-weighted image.

curdled material was seen when the spleen was open. Since TB was not on our list of differential diagnoses initially, only intravenous levofloxacin was given for 1 week after surgery and the patient was discharged. Postoperative pathology showed intrasplenic granulation accompanied by necrosis, and negative acid-fast staining (Figure 2). Twenty days after the surgery, the intraoperative pus culture demonstrated positive bacillus growth. The patient had not received any anti-TB medications at this point.

The patient developed a fever 2 months after surgery. Physical examination showed a temperature of $38^{\circ} \mathrm{C}$, headache, no obvious nausea or vomiting, no loss of consciousness, and no myoclonus. MRI indicates a $4.0 \times 3.3 \mathrm{~cm}$ mass in the right frontal lobe. The right ventricle was deformed with a left midline shift. No changes were observed in the other ventricles and cisterna. The diagnosis from the MRI was intracranial abscess (Figure 3). Lung computed tomography (CT) suggested multiple pulmonary nodular lesion and pulmonary cavitation (Figure 4). A complete blood count showed a white blood cell count of $10.6 \times 10^{9} / \mathrm{L}$, platelet count of $792 \times 10^{9} / \mathrm{L}$, and C-reactive protein of $11.0 \mathrm{mg} / \mathrm{L}$. Cerebrospinal fluid analysis showed chloride of $128 \mathrm{mmol} / \mathrm{L}$, glucose of $3.3 \mathrm{mmol} / \mathrm{L}$, and proteins of $1.13 \mathrm{~g} / \mathrm{L}$. The diagnosis of a TB intracranial abscess and pulmonary TB after splenectomy for a TB abscess was made, and the HRZE (isoniazid $300 \mathrm{mg}$ qd, rifampin $450 \mathrm{mg}$ qd, pyrazinamide $500 \mathrm{mg}$ tid, and ethambutol $750 \mathrm{mg} \mathrm{qd}$ ) regimen was started immediately. Twenty days later, chest CT indicated a significant shrinkage of the pulmonary loci, and the patient's head MRI showed a slight decrease in the size of the intracranial abscess. Anti-TB regimen was
A

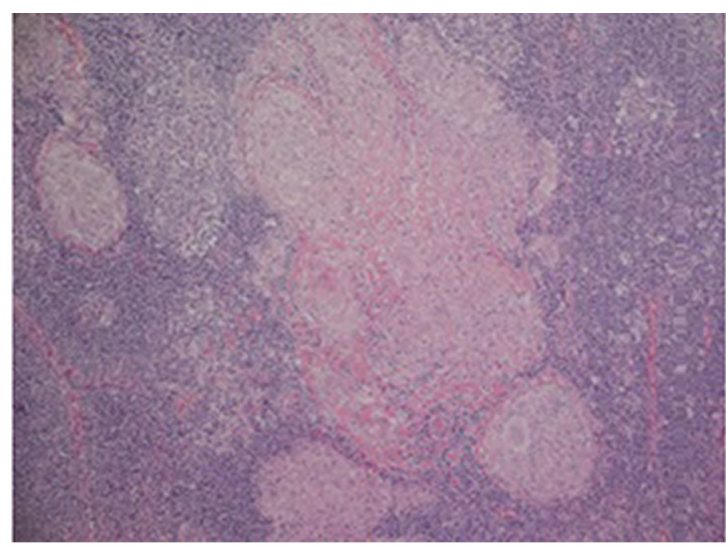

B

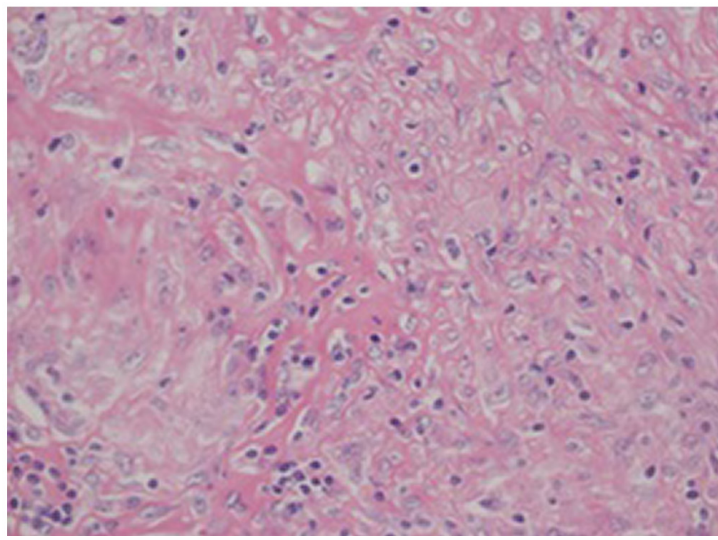

Figure 2 Postoperative pathology of spleen.

Notes: A: magnification $\times 10$; B: magnification $\times 40$.

discontinued 1.5 years later. Regular follow-up showed a complete resolution.

This case report was approved by the ethics committee of The First Affiliated Hospital, School of Medicine, Zhejiang University, and the patient provided their agreement and written consent to this report being published.

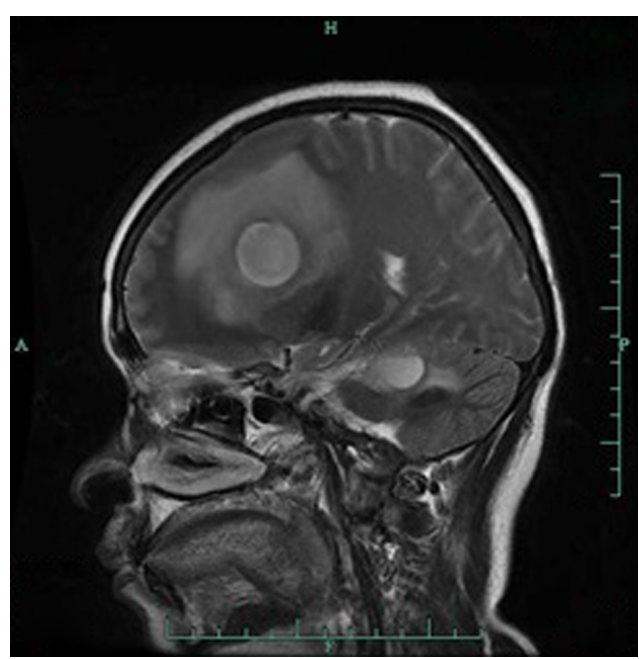

Figure $3 \mathrm{~T} 2 \mathrm{WI}$ of head MRI showing mass in the right frontal lobe. Abbreviations: MRI, magnetic resonance imaging; T2WI, T2-weighted image. 
A

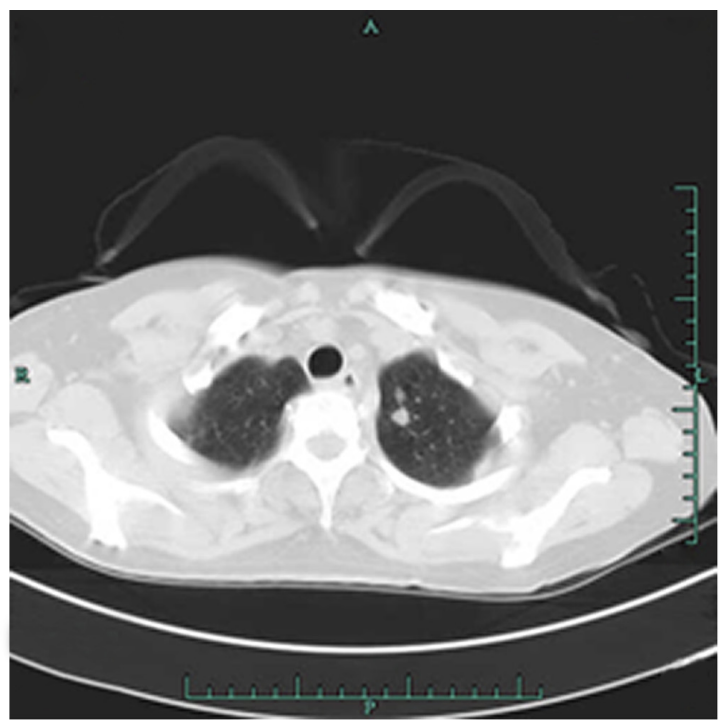

B

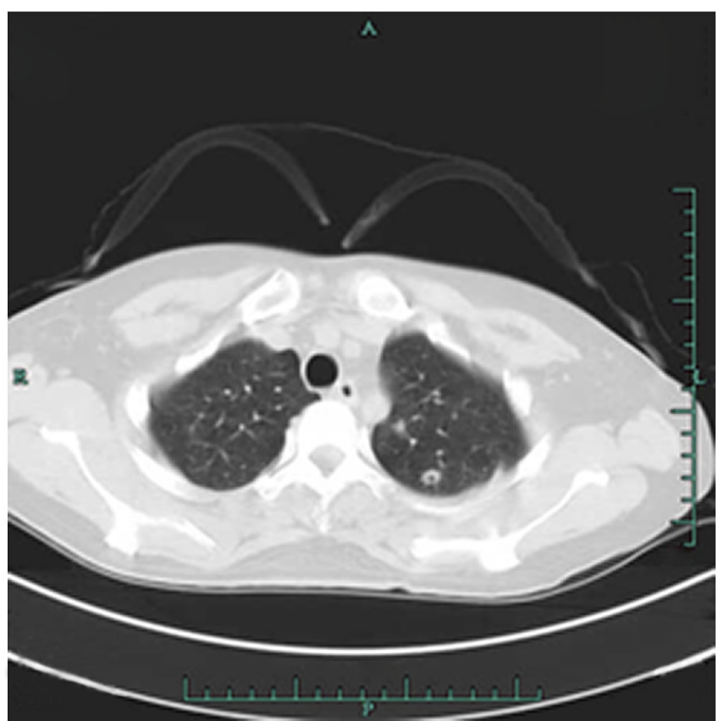

Figure 4 Chest CTs showing multiple pulmonary nodular lesion (A) and pulmonary cavitation (B). Abbreviation: CT, computed tomography.

\section{Discussion}

The incidence of splenic TB is very low. It is often secondary to pulmonary, peritoneal, or intestinal $\mathrm{TB}$, and is caused by blood dissemination of Mycobacterium tuberculosis. ${ }^{1,2}$ Solitary splenic TB is even more rare, which is often preceded by an immunocompromised condition. Published cases occurred in patients with human immunodeficiency virus infection, systemic lupus erythematosus, hematological conditions, and patient's using corticosteroids. ${ }^{3-5}$ The diagnosis of solitary splenic TB is made mainly through postoperative pathological analysis of the spleen postsplenectomy. Some diagnoses are confirmed by intrasplenic fine-needle aspiration or, in a very small number of cases, by empiric anti-TB therapy. ${ }^{6,7}$ The patient in this case report had no underlying diseases, usage of any immunosuppressive agents, or any other clinical manifestations indicative of TB, such as low-grade fever, weight loss, or abdominal pain. Due to multiple intrasplenic masses found by an abdominal ultrasound and CT scan, the preoperative impression was splenic angioma. Intraoperative findings, however, were consistent with a massive collection of intrasplenic pus and disseminated intra-abdominal tubercles. The pathology laboratory test and pus culture indicated necrotic granulations and bacillus growth, respectively. Therefore, the affirmative diagnosis was solitary splenic TB. Unfortunately, the diagnosis was made 20 days after the surgery and no postoperative anti-TB agents were given, leading to disseminated TB, such as intracranial TB abscess and pulmonary TB. One and half years of anti-TB therapy was given, and the patient achieved a complete resolution. This case revealed that solitary splenic TB can occur in people without any underlying diseases or immunocompromised conditions, as well as in patients whose clinical manifestations are not indicative of TB. In addition, when radiological tests indicate a splenic abscess, a cold abscess should be on the differential list, because TB abscesses take longer to develop and symptoms are often atypical compared to bacterial abscesses. When the diagnosis of TB is confirmed, a complete anti-TB regimen has to be started immediately to avoid systemic dissemination of TB.

\section{Acknowledgments}

This study was supported by grants from the National Grand Program on Key Infectious Diseases (2012ZX10002-004).

\section{Disclosure}

The authors report no conflicts of interest in this work.

\section{References}

1. Zhan F, Wang CJ, Lin JZ, et al. Isolated splenic tuberculosis: a case report. World J Gastrointest Pathophysiol. 2010;1(3):109-111.

2. Imani Fooladi AA, Hosseini MJ, Azizi T. Splenic tuberculosis: a case report. Int J Infect Dis. 2009;13(5):e273-e275.

3. Dal MS, Dal T, Tekin R, Bodakci E, Duzkopru Y, Ayyildiz MO. Idiopathic thrombocytopenic purpura associated with splenic tuberculosis: case report. Infez Med. 2013;21(1):50-55.

4. Azzam NA. Splenic tuberculosis presenting as fever of unknown origin with severe neutropenia. Ann Clin Microbiol Antimicrob. 2013; $12: 13$

5. Pramesh CS, Tamhankar AP, Rege SA, Shah SR. Splenic tuberculosis and HIV-1 infection. Lancet. 2002;359(9303):353.

6. Meshikhes AW, Al-Momen SA. Laparoscopic diagnosis of splenic tuberculosis. Surg Laparosc Endosc Percutan Tech. 2006;16(5): 355-356.

7. Mandal SK, Ganguly J, Sil K, Chatterjee S. Isolated splenic tuberculosis in an immunocompetent patient. BMJ Case Rep. 2014;2014. 


\section{Publish your work in this journal}

Therapeutics and Clinical Risk Management is an international, peerreviewed journal of clinical therapeutics and risk management, focusing on concise rapid reporting of clinical studies in all therapeutic areas, outcomes, safety, and programs for the effective, safe, and sustained use of medicines. This journal is indexed on PubMed Central, CAS,

EMBase, Scopus and the Elsevier Bibliographic databases. The manuscript management system is completely online and includes a very quick and fair peer-review system, which is all easy to use. Visit http://www.dovepress.com/testimonials.php to read real quotes from published authors.

Submit your manuscript here: http://www.dovepress.com/therapeutics-and-clinical-risk-management-journal 